\title{
Does Ontology Matter?
}

\begin{abstract}
Andrew Graham
University of Missouri — Kansas City

DOI: $10.2478 /$ disp-2014-0004

BIBLID [0873-626X (2014) 38; pp. 67-91]

Abstract

In this paper, I argue that various disputes in ontology have important ramifications and so are worth taking seriously. I employ a criterion according to which whether a dispute matters depends on how integrated it is with the rest of our theoretical projects. Disputes that arise from previous tensions in our theorizing and have additional implications for other issues matter, while insular disputes do not. I apply this criterion in arguing that certain ontological disputes matter; specifically, the disputes over concrete possible worlds and coincident material objects. Finally, I consider how one could show that some ontological disputes do not matter, using a Platonism/nominalism dispute as an example.
\end{abstract}

\section{Keywords}

Ontology, metaontology, possible worlds, coincidence, platonism and nominalism.

\section{Introduction}

In recent times, a number of philosophers have argued for a variety of deflationary views concerning ontology (the study of what exists). For instance, some argue that ontological disputes are merely verbal or terminological, some that there are no objectively correct answers to ontological questions, some that ontological disputes are shallow or fail to be substantive. In response, other philosophers more sympathetic to metaphysics have developed ways of defending ontology from these charges. ${ }^{1}$

In this paper, I will consider a question which is closely related to many of these metaphilosophical disagreements: does ontology mat-

\footnotetext{
${ }^{1}$ For a selection of papers defending these and other views about ontology, see the recent volume edited by David Chalmers, David Manley and Ryan Wasserman 2009.
}

Disputatio, Vol. VI, No. 38, May 2014

Received: 02/08/2013 Accepted: 18/11/2013 
ter? I suspect that this question is at the root of such disagreements because I think many deflationary philosophers are motivated by the feeling that ontological speculation is pointless and irrelevant. Even setting aside this psychological conjecture, the questions of whether and why ontology might matter are interesting in their own right and yet have not been addressed directly by the participants in these disagreements.

I have three aims in this paper. The first is to articulate a criterion for deciding whether some dispute matters or not. The second is to argue that on this criterion, many familiar ontological disputes do matter. In particular, I will argue that the dispute over the existence of concrete possible worlds and the dispute over coincident material objects (like a statue and its clay) both matter. The third is to discuss how one might demonstrate that some other ontological disputes do not matter, using a version of the Platonism vs. nominalism dispute as an example.

\section{When Does a Dispute Matter?}

To begin, I will articulate a criterion for deciding whether a dispute matters or not. To make things simpler, I will call disputes that matter 'significant' and disputes that do not matter 'insignificant.' So, what we are looking for is a way to understand the distinction between significant and insignificant disputes, but to do so we should first get clear about the relevant sense of 'matters' or of 'significant.' We can get a rough handle on this by noting that significant disputes are those that are worth taking seriously, or paying attention to, or investing time and effort in, and insignificant disputes are those that are somehow defective in ways that make them not worth taking seriously. ${ }^{2}$

\footnotetext{
${ }^{2}$ It is worth emphasizing that I am using 'significant' in a somewhat technical sense. 'Significant' is sometimes used to mean something like meaningful or contentful, as in the claim that nonsensical sentences lack significance. That is not how I am using it. I am using it more in the sense of important or worthwhile, in the way that a comment might make a significant contribution to a discussion while other comments might fail to do so, even though they are all perfectly meaningful.
} 
There are, however, different ways a dispute might matter. A dispute over how many votes a candidate has received is significant for primarily political reasons; it bears on who can legitimately govern. A dispute over which route to the airport is the quickest is significant for primarily practical reasons; it bears on how to avoid being late for one's flight. A dispute over the age of the Earth is significant for primarily theoretical reasons; it bears on which theories we should accept in geology, physics, and biology. These different ways of being significant may not always be cleanly separable, but the one I am most interested in is best captured by the last example. There is also a correlative sense of 'insignificant,' applicable to those disputes that lack the relevant feature. Though most disputes over the age of the Earth are significant in the relevant sense, a dispute over the age of the Earth down to the billionth decimal place may not be.

It is also natural to speak of a dispute's mattering or being important to or for somebody, or relative to certain interests, and so there may be a corresponding sense of 'significance.' A dispute over the identity of my great, great grandfather might be significant to me (if I have an interest in genealogy), but not to many other people. When it comes to ontology, I have in mind a more impersonal notion of significance. Ontology may well matter to particular people and not to others, but there is an additional question of whether it matters in general. In saying that a dispute over the age of the Earth is significant, we need not think that it is significant to or for any specific person or relative to any particular set of interests (except, perhaps, very general interests, like figuring out what is true).

In looking for way to determine whether disputes are significant in this theoretical and impersonal sense, I think the proper approach is to look at the (theoretical) roles played by the disputes. My suggestion is that whether a dispute is significant depends on how it hooks up with the rest of our theoretical projects. In particular, the important thing is whether the dispute is the product of tensions arising from previous theorizing and whether its resolution would have consequences for other theoretical issues by, for instance, helping us answer other questions, resolve other disputes, open new lines of inquiry, and so on.

Call disputes which are connected with the rest of our theoretical projects in this way 'integrated,' and those that lack such features 
'insular.' My suggestion is that integrated disputes are significant, while insular disputes are insignificant. Disputes become significant by being integrated into our broader theoretical projects.

For our purposes, the important claim is that integration is sufficient for significance. As above, I will also often claim that insular disputes are insignificant, but here I am less certain. If insularity makes for insignificance, then integration is necessary for significance. In that case, there are no intrinsically significant disputes, disputes that matter just for their own sake and not due to connections with the rest of our inquiries. I think this view can be defended, but I recognize that it is much more controversial than the simpler claim that integration is sufficient for significance. The more controversial claim is inessential for most of the arguments later in the paper, so although I may appeal to it on occasion, those who reject it can still find room to agree with my main claims concerning the significance of ontological disputes.

Although this view can help guide us in classifying disputes, it is admittedly rough, since the characterization of integration is rough. However, I do not think that we should seek out a more precise account. Even a rough characterization can yield a precise classification of a wide range of cases and I see no simple way to codify the great variety and complexity of factors on which a dispute's significance might depend.

That being said, let me note some features of the view that shed more light on it and remove the temptation to look for a perfectly precise account. The first is that whether a dispute is integrated cannot always be determined a priori, because its theoretical role cannot always be known a priori, or prior to actually pursuing the dispute to its natural terminus and discovering how it bears on other theoretical projects. Therefore, whether a dispute is significant cannot always be known a priori either. I think that is the correct result. It would, on the contrary, be amazing if one could distinguish the worthwhile disputes from the empty ones merely by reflecting on them in the abstract. We certainly cannot do this in other areas of inquiry, like physics or math (we cannot, for instance, pronounce that some research program is fruitless before even considering what results it may have). Rather, we must see how the disputes play out, how they affect other areas of inquiry, whether they produce fruitful 
lines of research, and so on. The upshot is that one reason for looking for a precise account of significance - the desire to determine $a$ priori whether some dispute is worth engaging in, before getting our hands dirty — is misguided.

A second feature of the view is that integration is an extrinsic property of disputes. Whether a dispute is integrated does not depend merely on the features of the dispute itself, such as what the sentences are that it targets, what languages are used, and who the participants are. Rather, it depends on the wider theoretical context: what prior research produced the question, what prior commitments led the parties to disagree, what lines of research their positions might produce, how their positions bear on commitments in other areas of inquiry, and so on. So, on the view that integration is sufficient for significance, a dispute's significance is typically a matter of how it relates to our inquiry more generally and not what the dispute itself, in isolation from the rest of our theorizing, is like.

A consequence of this observation is that any dispute, individuated by its intrinsic features, could be significant (or fail to be), so long as it occurs against the proper theoretical background. Some might find this implausible, but I think it is correct. It is not difficult to imagine contexts where an important theoretical question hangs on even the most silly-seeming issue. Imagine arguing about whether every true sentence can be rewritten in subject-predicate form (e.g. 'A is thus and so'). In most contexts, this question does not matter and an effort to establish whether such equivalences held would be a waste of time (imagine, for instance, someone insisting on making sure that an article submitted to a physics journal could be completely rewritten in that form before publishing it). Nonetheless there are contexts where it is very important: if we are evaluating Leibniz's theory of truth (according to which 'an affirmation is true if its predicate is contained in its subject, ${ }^{, 3}$ ), or his defence of

${ }^{3}$ G. W. Leibniz, quoted in Benson Mates (1986: 84). There are various other formulations of this idea by Leibniz, for instance: 'in every true affirmative proposition, necessary or contingent, universal or singular, the concept of the predicate is included in some way in that of the subject, praedicatum inest subjecto.' (quoted in Robert Adams (1994: 57)) and 'the predicate... is always in the subject... and the nature of truth in general... consists in this very thing.' (Leibniz 1686: 31). I am not a Leibniz scholar, so I stand open to correction if I have mis- 
nominalism, ${ }^{4}$ then this is precisely the question to ask. Another example: Ann and Bert disagree as to whether, during the September 11, 2001 terrorist attacks on the World Trade Center, there was one destructive event (involving both towers) or two destructive events (each involving a single tower only). For many purposes, such as deciding how to describe the event in a history textbook, this is beyond pointless. Yet it might matter a great deal for the purpose of settling an insurance claim, depending on how it is worded (there could, for instance, be limits on how much is paid per destructive event.)

That significance is extrinsic defuses another reason for wanting a precise and systematic account: the thought that we can settle, once and for all, which disputes are significant. If significance is extrinsic, then a dispute could be significant in one context and not in another, so long as the theoretical background shifts accordingly. Our account of significance should be flexible enough to accommodate those shifts.

Even with these clarifications, it should be clear that I have not provided strict necessary and sufficient conditions for whether a dispute is integrated, and so have not provided a foolproof methodology for determining whether a dispute is significant. Although this may be true, I do not think it should worry us because, if my view is correct, no such methodology is expected or needed. Not expected, because there are many ways that a dispute can be relevant to our theorizing and there is no reason to think that they can all be subsumed under a single methodology. Not needed, because whether a dispute is significant depends on factors that we are antecedently good at detecting (as should become plausible in the next few sections when we apply the view to some specific examples). That does not, of course, mean that there will not be hard cases, but the difficulty here is the sort that arises whenever we must rely on our judgment rather than

represented his views.

${ }^{4}$ Here I am following Benson Mates, who writes: 'The propositions ordinarily considered most basic by Leibniz are those expressed by simple sentences of the form 'A is B,' possibly supplemented by the quantifiers 'some,' 'no,' or 'all.' He seems to think — because of his nominalistic metaphysics, as I conjecture that whatever can be said at all can be expressed in such propositions.' (Mates 1986: 54) 
on some predetermined decision procedure. On my view that sort of difficulty may well be ineliminable, but I think that will be so on any reasonable view. Trying to determine which disputes are significant is like trying to determine which horses to bet on; there are no wholly foolproof criteria that could provide a fixed methodology, but we can make clear what considerations are relevant and refine our judgments nonetheless.

Some questions remain concerning the relationship between significance and various other features of disputes explored in the recent literature on metaontology. More specifically, philosophers have given accounts of what it is for disputes to be merely verbal or factual, for disputes to be substantive ('deep') or shallow, for disputes to concern the fundamental or the non-fundamental, and so on, and have asked whether ontological disputes have these features. So, we might naturally wonder how significance relates to these various different qualities. For example, must a dispute be non-verbal for it to be significant? Are all substantive disputes significant? To some extent, I will remain neutral on these questions, but I suspect that whether a dispute is significant is independent of which of these other features it might possess, meaning that the question of significance can be answered independently of these other questions concerning verbality, substantivity, and related notions. One might have doubts about this independence; for instance, it can seem plausible initially that verbal disputes are never significant. However, one might argue that some verbal disputes are integrated and so significant after all. We might, for instance, imagine a disagreement between two members of some organization about whether John was late to the meeting. The disagreeing parties might nonetheless agree about the exact time at which John arrived, making the dispute appear verbal (it seems to concern nothing but the extension of the term 'late'). Despite this, the dispute might still be significant, since it might have important consequences for various other questions, such as whether John will be punished, whether others will be counted as late, how the rules concerning lateness will be enforced in the future, and so on. Similarly, non-verbal (or factual) disputes are not always significant. Two people might disagree about how many blades of grass are in my yard, yet without some further story about what hangs on this dispute, it seems insular enough to render it insignificant. The 
relationship between significance and notions like substantivity or fundamentality is more difficult to assess, but as with verbality, I think the question of significance and the questions of substantivity, depth or fundamentality are largely independent of one another. ${ }^{5}$ So, in what follows, I will act on the assumption that we can determine whether a dispute is significant without first having to settle where it falls on these other classifications (e.g., whether it is verbal or factual, substantive or shallow, etc.).

\section{The Significance of Ontological Disputes}

On my account, to determine whether some ontological dispute matters, we need to determine whether it is integrated. As this formulation suggests, the question of whether ontological disputes are significant is best tackled on a case-by-case basis. It may well be that some ontological disputes are integrated and others are not. I suspect that many ontological disputes are integrated. I do not, however, have space to defend the significance of a great many disputes in this paper. Instead, we will examine two particular ontological disputes. I will argue that each is integrated in a way that renders it significant. The first of these two is the dispute over concrete possible worlds. Since the significance of this dispute is less controversial than many others in ontology, this case will serve mainly as an illustration of the idea that theoretical connections are what makes for significance and to motivate the idea that ontological disputes can have such connections. I will then turn to a more controversial case, the case of coincident material objects like a statue and its clay. Much of what I will say regarding the details of these disputes is not entirely novel, but the aim is to gather together these observations for the novel purpose of demonstrating that these disputes matter.

\subsection{Possible Worlds}

The dispute in question is that between modal realists, like David Lewis, and actualists, like Alvin Plantinga, Robert Stalnaker, and others, over the existence of concrete possible worlds of the sort

\footnotetext{
${ }^{5}$ I defend this independence more carefully in Graham (forthcoming).
} 
Lewis famously defends. ${ }^{6}$ The dispute is ontological, since it concerns the existence of objects of a peculiar kind, yet I think there is less temptation to think that it is insignificant compared to examples more frequently discussed in the metaontology literature, such as the persistence and composition debates. The reason, I think, is that the wider theoretical relevance of the dispute concerning possible worlds is more obvious than in those cases. Here I will point out some of the ways in which it is relevant.

Let us begin with its source. What, for instance, are Lewis's motivations for accepting his account of possible worlds, in contrast with the actualist alternatives? In On the Plurality of Worlds, Lewis considers a wide range of theoretical work that possible worlds can perform. ${ }^{7}$ He notes that they can be used in explicating modal notions (including not just necessity and possibility but counterfactuals and causation as well), in developing a theory of content for speech and thought, in a theory of properties, and so on. In many of these cases there is agreement between Lewis and actualists about the role possible worlds can play, but two cases that are especially important to Lewis set them apart. One, which appears again and again in $O n$ the Plurality of Worlds, is eliminating primitive or unanalyzed modality. The second is giving a purely extensional theory of properties.

Regarding the first, Lewis's thought is that modal notions can be explicated in terms of possible worlds (e.g. necessity can be understood as truth in all possible worlds) and possible worlds in turn can be understood in non-modal terms. They are simply concrete universes, of the sort we inhabit, that are spatiotemporally isolated from one another. No primitive modal notions are needed. ${ }^{8}$ On the second point, Lewis favours a set-theoretic conception of properties. ${ }^{9}$ Though attractive, the view that properties are just the sets

${ }^{6}$ For Lewis's views, see Lewis 1986. For actualism, see Platinga 1974, 1976, chapter 3 of Stalnaker 1987, and Stalnaker 2003.

${ }^{7}$ See especially the first chapter of Lewis 1986.

${ }^{8}$ That is, at least, how the picture is meant to work. I want to set aside, for now, the question of whether Lewis really succeeds in eliminating any primitive modality and focus instead on the intended contrast between his view and those of his opponents.

${ }^{9}$ At times, he flirts with more robust conceptions of properties as universals 
of their instances (and that every set is a property of its members) is open to the well-known objection from the existence of distinct yet co-extensive properties, as in the famous example of creatures that have hearts and creatures that have kidneys. Having a heart and having a kidney are distinct properties, but the sets in question are identical, assuming they have the same members. Lewis's plurality of concrete possible worlds gives him a way out of the problem: take properties to be sets of individuals from all possible worlds. Assuming that these properties are not necessarily co-extensive, there will be individuals in some worlds that have one but not the other and the sets will be distinct.

These two applications of possible worlds set Lewis's view apart from actualists who accept an ontology of non-concrete or abstract possible worlds, which exist in the actual world. His primary objection to each of the actualist (or, in his terms, ersatz) alternatives he considers is that it is incapable of dispensing with primitive modality. In each case, some sort of primitive modal notion is needed to make sense of what the actualist's possible worlds are. For instance, in the version of actualism that takes possible worlds to be sets of sentences of some kind, one needs a notion of consistency to distinguish between those sets of sentences that serve as possible worlds and those that do not (an inconsistent set of sentences could at best be an impossible world). But, Lewis argues, consistency is a modal notion since it signals that the sentences in question could all be true together. We might explain it by saying that a set of sentences is consistent if there is a world where they are all true together, but that would be circular for the actualist in question. So some notion of consistency must be taken as primitive (or some other modal notion taken as primitive, in terms of which consistency can be explained). ${ }^{10}$

Similarly, it is clear that actualists cannot take properties to be sets in the straightforward way without running afoul of the co-extension problem. Many actualists adopt a more realist attitude towards properties, taking them as primitive in some way (some even

(see Lewis 1983), but generally he relies on the set-theoretic view.

${ }^{10} \mathrm{I}$ am oversimplifying here by ignoring attempts to formulate a syntactic notion of consistency. Lewis discusses this in more detail in section 3.2 of Lewis 1986. 
employ them in their account of what possible worlds are, as in Stalnaker (1987: 46)).

The suspicion of primitive modality and the set-theoretic conception of properties are related since both find their motivation in the broad empiricist tradition that regards modality and intensionality as somehow mysterious or objectionable. Furthermore, they rest on the view that at least conceptually there is a distinction between the modal and the non-modal, for otherwise the project of eliminating primitive modality is hard to make sense of.

In contrast, rather than viewing it as a disadvantage of their position, many actualists are happy to accept unreduced modality and properties. Actualists often view modality in particular as pervasive and primitive. Far from mysterious, modal notions form part of our ordinary conception of the world, and although they might stand in need of some regimentation for theoretical purposes, conceptually they are no more problematic than so-called 'non-modal' notions. I say 'so-called' because many actualists also endorse the view that there is no sharp distinction between the modal and the non-modal, or that many apparently non-modal notions are in fact modal, at least in the sense that a proper understanding and application of them involves understanding certain modal facts. As a result, many actualists view the project of eliminating primitive modality as misguided, manifesting a misunderstanding of modality. Without this motivation, there is less reason to think of possible worlds as concrete universes, especially when combined with a willingness to take properties (or similar abstract entities like states of affairs or essences) as primitive, rather than reducing them to sets. Those entities can then be used to make sense of our talk of possible worlds.

Hence the dispute over concrete possible worlds has its source at least in part in competing conceptions of modality and the prospects for its reduction. Much of the motivation for adopting a Lewisian ontology stems from an aversion to primitive modality and intensionality. Those who do not share this aversion are free to adopt alternative conceptions of possible worlds, as many actualists do, since although actualists and modal realists agree about many of the theoretical roles that possible worlds should play, providing a non-modal ground for modal notions is not a shared goal. Although the dispute is ontological, it arises naturally out of prior commitments outside of ontology. 
Other prior disagreements are also relevant (for instance, different views about the epistemological and metaphysical significance of the concrete/abstract distinction), but let me turn from the source of the dispute to its consequences. Some of its consequences are obvious from the foregoing: how the dispute plays out will affect what theoretical roles possible worlds can play. For instance, those who accept concrete possible worlds can offer extensional accounts of various apparently intensional phenomena, like properties, but also counterfactuals, causation and so on. That in turn has consequences for what kind of language and ideology we employ in our theorizing, or which and how many primitive terms we must employ. Other consequences are less obvious from the foregoing, but still important. The parties to the dispute might be committed to different treatments of de re modality (counterpart theory vs. more straightforward accounts of transworld identity), to different views about which modal claims are true or false or meaningful at all (see, for instance, Alan McMichael 1983), to different semantics for terms like 'actual,' and so on. Rather than discuss these connections in detail, my aim is to draw attention to the fact that it is because of these points of contact with other areas that many people are inclined to take the dispute over concrete possible worlds seriously. The dispute has important ramifications for our theorizing in various domains and its significance is due to those connections. So, I think the case serves as a model for how to think about the significance of ontological disputes more generally.

\subsection{Coincident Objects}

Consider the following disagreement. An artist has two lumps of clay, one shaped like the upper half of Goliath, and the other shaped like the lower half. At noon, the artist puts them together, thereby creating both a new lump of clay and a new statue of Goliath, which he names 'Lump' and 'Goliath,' respectively. At 1:00, he smashes the clay, thereby destroying both Lump and Goliath. Two people observe these events, and are asked: from noon to 1:00, were there two, coincident things, or was there only one thing? The first (who we will call '2-thinger') answers that there were two, and the second ('1-thinger') that there was one. 
I will use the same strategy as in the last section to argue that this dispute is significant. To do so, we need to see how the dispute is a natural result of prior theoretical commitments and how it has ramifications for other areas of inquiry outside of ontology.

First, in a dispute like this the participants are brought to their positions by reflecting on a paradox and their positions represent different ways of coping with genuine tensions in their beliefs. For instance, suppose that prior to their disagreement both 1-thinger and 2-thinger began by accepting the following three claims:

1. Leibniz's Law (if $\mathrm{x}$ is identical to $\mathrm{y}$, then $\mathrm{x}$ and $\mathrm{y}$ have all the same properties).

2. Distinct material objects cannot occupy exactly the same region of spacetime.

3. Lump could have survived changes that Goliath could not have survived and vice versa.

From these claims, we can derive a contradiction, as follows: Lump and Goliath both occupy exactly the same region of spacetime and so, by claim 2, they are identical. We can also assume, as an instance of claim 3, that Lump could have survived being squashed into a ball while Goliath could not have survived that change. However, given Leibniz's Law, it follows from the identity claim just established that Goliath could have survived being squashed into a ball, while Goliath could not have survived that change, which is inconsistent.

2-thinger and 1-thinger's divergent reactions to the case can be seen as divergent attempts to resolve this paradox. 2-thinger abandons the claim that material objects cannot spatiotemporally coincide (claim 2), while 1-thinger denies that Leibniz's Law applies in this case, perhaps by reinterpreting the sentences attributing modal properties to Lump and Goliath so that they do not attribute the same properties when different names are used to pick out the thing in question. She thereby blocks the inference from the identity of Lump and Goliath, plus Leibniz's Law, to the inconsistent modal claim. 2-thinger's reaction leads him to think that Goliath and Lump are distinct but perfectly coincident, while 1 -thinger's leads her to think that Goliath and Lump are identical, even though something can be true of that thing qua Goliath that is not true of it qua Lump and vice versa. 
That the disagreement is prompted by different reactions to a tension in their beliefs lends some support to the claim that the disagreement is significant, but we should also consider what ramifications their positions have for questions beyond the dispute itself, including some issues in the philosophy of language. A number of such connections have been explored in the literature on such cases, but I will summarize some of them in order to make their relevance clear. ${ }^{11}$

One consequence is that 2-thinger and 1-thinger are committed to different conceptions of de re modal predication. 1-thinger's response to the problem requires her to adopt a semantics on which one cannot simply substitute co-referring proper names in de re modal predications while preserving truth-value. Given that she accepts that Goliath = Lump, such a semantics is required to block the inference from 'Lump could survive a change that would destroy Goliath' to 'Goliath could survive a change that would destroy Goliath.' There are different ways of achieving this goal; one familiar route would be to adopt a Lewisian semantics in terms of counterparts, but there are other options. The unifying idea behind these options is that the properties attributed to a thing by predicates like 'could survive being squashed into a ball' vary along with the name used to pick out that thing, so that the same predicate can apply to a thing under one name and fail to apply under another name. In that case, despite the fact that the same predicate is used in both the consistent and the inconsistent predications, the same property is not being attributed by those predications, and so Leibniz's Law cannot be used to derive a contradiction. On a counterpart semantics, the property picked out by the predicate depends on the counterparts picked out by the counterpart relation: 'could survive being squashed into a ball' picks out the property of having this counterpart (the one picked out by the relevant relation), who survives being squashed into a ball. Furthermore, if one thinks that the counterpart relation is fixed, at least in part, by how one refers to the object in question (e.g. 'Goliath' fixes the statue counterpart relation, while 'Lump' fixes the lump of clay

\footnotetext{
${ }^{11}$ For some representative discussion, see David Wiggins 1968, Alan Gibbard 1975, chapter 4 of Lewis 1986, Theodore Sider 2001, Kit Fine 2003, and Karen Bennett 2009.
} 
counterpart relation), then the property attributed varies along with the name, since the name varies the counterpart relation.

Thus 1-thinger will be committed to various theses in the philosophy of language (exactly which theses will depend on how she spells out her view). She maintains metaphysical consistency by adjusting her semantics. 2-thinger, on the other hand, incurs no such commitments from his view; he might adopt those views for independent reasons, but as far as this dispute is concerned, he is free to treat de re modal predications as he likes.

This particular consequence is really an instance of a more general consequence. The divergence between their views will not be isolated to the semantics of modal claims. Following Fine 2003, there is reason to think that modal properties are not the only properties that (seem to) distinguish Lump and Goliath. Depending on the case, it might be that Goliath is poorly made but Lump is not, or that Goliath is valuable but Lump is not, or that Goliath is well insured but Lump is not, or that Goliath is the referent of 'Goliath' but Lump is not, and so on. If so, and if 1-thinger appeals to the same strategy for dealing with these cases, then predications like 'Goliath is valuable,' 'Goliath is poorly made' and 'Goliath is the referent of 'Goliath', as well as many others, will require special semantic treatment, in the same way as de re modal predications. The result will be an even greater divergence between 2-thinger's and 1-thinger's views in the philosophy of language.

Another, related consequence of the dispute is that 2-thinger and 1-thinger are committed to different views about identity. In particular, they are committed to different answers to the question of whether identity can be contingent. 1-thinger is committed to the claim that identity can be contingent, in the sense that the following can be true: Goliath is identical to Lump, but there is a world where Goliath and Lump both exist yet are not identical. Generally, that is because 1-thinger thinks that Goliath and Lump are identical yet have different modal properties (e.g., Lump could survive being squashed into a ball but Goliath could not). We can assume that in some world the relevant difference is realized: the thing is squashed, Lump survives, and Goliath does not. In that world, the two are not identical, yet both exist (at some time or other). Alternatively, continuing in a Lewisian vein, depending on the counterpart relation in 
question there may be a world where the thing in question has two distinct counterparts, one a lump of clay and one a statue, thus making true the claim that Lump and Goliath could have been distinct. 2-thinger, on the other hand, is not committed to any such views about identity. ${ }^{12}$

These consequences have further consequences. A disagreement over whether there can be contingent identity will generate disagreements about what is possible, and disagreements concerning the space of possible worlds can generate disagreements over what is intelligible or conceivable. A simple example is that 2-thinger and 1-thinger might disagree about whether it is conceivable for Goliath and Lump to be distinct. These disagreements open up the possibility of more interesting disagreements; for instance, 1-thinger's commitments remove at least one barrier to the intelligibility of certain theses in the philosophy of mind (like the view that mental states are contingently identical with brain states or that persons are contingently identical with their bodies), theories that 2-thinger should find unintelligible in principle.

There are additional consequences of the disagreement that are somewhat more general and difficult to pin down. One is that 2-thinger and 1-thinger are committed to different views about how our epistemic situation constrains the existence claims we can justifiably accept. For instance, 2-thinger thinks that there can be two distinct objects even if there are no observational differences between them and no way to detect, by ordinary empirical means, that there are two things rather than one. This commitment might require him to reject some (perhaps naïve) versions of verificationism or antirealism. Regardless of whether there is a specific view that

${ }^{12}$ Putting this point in terms of contingent identity might be a bit misleading. 1-thinger need not accept that identity can be contingent in the sense that Saul Kripke 1971 famously argued against. On the Lewisian version of this view, the claim that Goliath and Lump are contingently identical can be understood as shorthand for the real story in terms of counterpart relations, and since a thing and its counterparts in other worlds are never really identical, there is a clear sense in which there are no contingent identities in Lewis's system. Nonetheless, putting things in terms of contingent identity is not entirely inaccurate either, especially since people who adopt the 1 -thing view often characterize their view in those terms (see, for instance, Gibbard 1975). 
he must reject here, 2-thinger and 1-thinger's disagreement might lead to additional disagreements over certain epistemic claims concerning when we are justified in believing identity claims (or their negations), how we distinguish objects from one another, and so on.

Once we see what prompts the disagreement between 1-thinger and 2-thinger, and what additional disagreements are prompted thereby, it becomes highly plausible that the dispute is significant. Its resolution would have an impact on the philosophy of language, philosophy of mind, epistemology, and other areas of inquiry. In my discussion I have focused on a fictional dispute, but the details are drawn from actual disagreements between philosophers. Of course, in actual philosophical disputes, it can be difficult to neatly separate out what, exactly, is the source of a dispute, what is a consequence of it, and what is an argument used to defend a view, but the connections between the dispute and our wider theoretical concerns are fairly clear.

How many other familiar ontological disputes are significant on this view is a question that I will leave unanswered for now. As I hope is clear from the above, answering this question in difficult cases such as the dispute over when and how often composition occurs will require careful attention to the details of the case in question. I cannot discuss all the interesting cases here, though I expect that many other familiar disputes will turn out to be significant, once we look carefully at the puzzles that produce them and the consequences they might have for various other branches of philosophy.

\section{Insignificant Ontological Disputes}

So far I have been defending the significance of certain ontological disputes by examining how they are integrated into wider theoretical projects. Although I think many more ontological disputes are significant, I also think it is important to recognize that not all ontological disputes need be significant.

It is difficult, however, to establish that any dispute is truly insignificant and so ought to be abandoned. My view of significance naturally leads one to hesitate before pronouncing some dispute insignificant, since new developments in the dispute, or in other areas of inquiry, always have the potential to expose or create connections 
between that dispute and others. So in claiming that some dispute is insignificant, there is always a real risk that one's judgment is premature. The same might be said for significance: that a currently significant dispute might become less integrated as our inquiries evolve. This is certainly possible, but the risks of failing to recognize the potential for such changes is greater in the case of insignificance than in the case of significance. Even if a significant dispute loses its connections and so becomes insignificant, it will always have been significant, at least for a time, and so our interest in it was not misguided. At worst, the danger is that we might continue to pursue some dispute after its relevance has been exhausted. In contrast, the danger in the case of proclaiming that some dispute is insignificant is that we can be discouraged from pursuing some issue which is either integrated in some undiscovered way or which, though currently insular, will later become integrated as our inquiries change. So, there is a risk that we will fail to pursue what could become fruitful lines of research. It is because of this greater risk that I emphasize the possibility that our judgments concerning insignificance can be premature and liable to change.

Keeping this in mind, it can still be useful to consider what kinds of evidence can support the claim that a dispute is insignificant. To do so, I will offer a reason for thinking that a particular ontological dispute is insignificant. The aim is not to defend the view that this dispute is insignificant. The reasons I will consider are far from a complete case in favour of insignificance, in ways that I will indicate. Rather, the aim is to illustrate how such a case might be made, by considering the kinds of reasons that one should seek in order to defend such a position.

We will focus on a specific ontological dispute because evidence is more compelling the more specific it is. It is easier to argue that specific ontological disputes are insignificant, rather than arguing from general principles that ontological disputes belonging to some broad category tend to be insignificant. The strategy is to offer reasons for thinking that the dispute lacks connections with the rest of our inquiry, so that it makes no difference which position in that dispute turns out to be correct (if either). Let us consider what that evidence might look like.

Consider the disagreement between nominalists and Platonists 
over whether mathematical objects, like numbers, exist. ${ }^{13}$ One common defence of Platonism - the view that mathematical objects exist - appeals to the theoretical indispensability of mathematical objects to natural science and our understanding of the world in general (as in, for instance, W.V.O. Quine 1948, 1951, 1960, and Hilary Putnam 1979a, 1979b). In response, some nominalists (most notably Hartry Field 1980) have tried to show how our scientific theories might be reworked to avoid reference to mathematical objects. I think it is plausible that a disagreement between Platonists and nominalists of this sort is significant (since it may have important effects on the shape of our scientific theories), but I mention it here only to set it aside. I want to focus instead on a different yet closely related disagreement.

Consider instead the disagreement between what we might call (following Mark Balaguer 1998) Full-Blooded Platonism and Fictionalist Nominalism. Full-Blooded Platonism is roughly the view that all (conceptually) possible mathematical objects exist (alternatively, all internally consistent mathematical theories are true). ${ }^{14}$ According to Fictionalist Nominalism, on the other hand, mathematical claims are not literally true, because mathematical objects do not exist. Instead, we think of ourselves as operating under the fiction that Platonism is true, and we count mathematical claims as true so long as they are true according to the fiction (or, roughly, would have been true had Platonism been true). This fiction is useful because it allows us to theorize about the concrete world in ways that we could not without it, and it constrains our use of mathematics in the same way that the truth of Platonism would. So on Fictionalist Nominalism, mathematical claims are literally false but we can nonetheless

\footnotetext{
${ }^{13}$ I intend for this to differ from the dispute over whether abstract objects of any sort (including properties, contents, and so on) exist, which I think is a different matter altogether.

${ }^{14}$ I say 'roughly' because there are difficulties with this formulation (for instance, anyone who thinks that the existence of mathematical objects is not a contingent matter will agree, reading the 'possible' as indicating metaphysical possibility). I think the formulation is clear enough for our purposes, but see Greg Restall 2003 for more.
} 
make sense of their usefulness in science and elsewhere. ${ }^{15}$

The defender of Full-Blooded Platonism holds that numbers exist while the proponent of Fictionalist Nominalism holds that they do not. Yet if developed in the right way, it is plausible that both Full-Blooded Platonism and Fictionalist Nominalism are fully consistent with our mathematical practice. Full-Blooded Platonism, on the one hand, seems to escape many of the traditional objections to Platonism that stem from our mathematical practice. For example, working mathematicians seem to require nothing but consistency and usefulness in order to regard some mathematical theory as true, but it is hard to find an epistemology for traditional Platonism that makes sense of this. Full-Blooded Platonism fares much better, for any consistent mathematical theory is true. On the other hand, Fictionalist Nominalism does not require us to rewrite our scientific theories in a language that does not quantify over numbers, unlike the other version of nominalism I mentioned above. Apparent reference to mathematical objects is explained as a descriptive aid and mathematical claims can be treated as true for all scientific purposes. So objections from the ubiquity and usefulness of mathematics in natural science do not threaten Fictionalist Nominalism. ${ }^{16}$

These observations suggest that Full-Blooded Platonism and Fictionalist Nominalism would have (or not have) the same effects on the rest of our inquiry. If so, they would require us to think differently about the question of whether numbers exist but not much else. Resolving the dispute one way or the other might have little effect on practicing mathematicians, scientists who employ mathematics, semanticists interested in understanding mathematical discourse, epistemologists interested in our knowledge of abstracta and other theorists. A full defence of this dispute's insignificance would require a more detailed examination of these possible connections,

${ }^{15}$ For more detail on the fictionalist strategy, see, among others, Steve Yablo 1998, 2002a, and 2002b, Balaguer 1998, Joseph Melia 2000.

${ }^{16}$ Some might complain that this requires us to adopt a less than fully serious attitude about science, regarding it as partly fictional. However, more recent developments of this approach dispense with the idea of fictions and appeal to independently motivated linguistic mechanisms to explain how mathematical claims can count as true even if numbers do not exist. See, for instance, Yablo 2009. 
but we see here the kind of consideration that counts in favour of insignificance. Even if the dispute between Fictionalist Nominalism and Full-Blooded Platonism is genuine, this kind of insularity would provide reason to think it is insignificant.

Another source of evidence for the insularity, and hence insignificance, of this dispute is the indifference we find amongst those most likely to be influenced by it (e.g., practicing mathematicians). For a dispute to be significant, it must have connections with other areas of inquiry. In some cases, it is clear where we should expect to find those connections. Questions about the existence of numbers should affect those areas of inquiry that involve numbers, if they have effects at all. Theorists who work in those areas are, therefore, the most likely to take an interest in the dispute (among those not engaged in the dispute itself). So, if we find that they are thoroughly disinterested in the dispute, we have some evidence that it lacks any connections and is thus insignificant. ${ }^{17}$

In this particular case, the question is whether mathematicians are concerned with the outcome of the Platonism vs. nominalism disagreement. The issue is a bit tricky, since the question should not be a purely sociological one. Many mathematicians do have views on the metaphysics of mathematics and some do let it affect their practice. Perhaps a better way to put the question is whether, from the perspective of working mathematicians, discovering that nominalism (or Platonism) is true would be compelling reason to abandon (or reconfigure in some nontrivial way) the field of mathematics. I think it is plausible that most would say no. It might require them to adjust their understanding of the metaphysics of mathematics, but it is doubtful that mathematics as a science would disappear or change dramatically. Consider, for instance, some remarks made by William Timothy Gowers in discussing the ontological status of ordered pairs in light of the availability of multiple set-theoretic reductions of them:

I would contend that it [whether there are ordered pairs] doesn't matter because it never matters what a mathematical object is, or whether it

${ }^{17}$ This is highly defeasible evidence, of course. We must assume that these theorists are aware of the dispute in question, that they understand it and have properly assessed its possible ramifications, and so on. 
exists. What does matter... about a piece of mathematical terminology is the set of rules governing its use. (Gowers 2006: 192)

In this particular example, we can see why the disagreement between Full-Blooded Platonism and Fictionalist Nominalism over the existence of ordered pairs is irrelevant to a mathematician like Gowers, for both agree on the rules governing mathematical terminology. Gowers goes on to say:

Suppose a paper were published tomorrow that gave a new and very compelling argument for some position in the philosophy of mathematics, and that, most unusually, the argument caused many philosophers to abandon their old beliefs and embrace a whole new -ism. What would be the effect on mathematics? I contend that there would be almost none, that the development would go virtually unnoticed. (Gowers 2006: 198)

We should not draw too strong a conclusion from the claims of a single mathematician, but Gowers's outlook supports the idea that working mathematicians are not very concerned with the outcome of the Platonism vs. nominalism dispute. ${ }^{18}$ That, I think, provides some evidence that the dispute would have no impact on mathematics, which in turn is some evidence that it is insignificant.

It would be premature to think that the observations made in this section establish that this particular ontological dispute is insignificant. There are at least two major areas where evidence for significance might be found. First, I have focused primarily on connections between this dispute and issues outside of philosophy (primarily in mathematics). So, a full defence of its insignificance would require more detailed consideration of possible connections with other issues in philosophy (especially in the philosophy of language and metaphysics). Second, the case for lack of connections with mathematics is still in its early stages. In giving a full defence of insignificance here, one would need to look more carefully at various forms of mathematical practice and their possible connections to the dispute in question. These issues are too complicated to be settled

${ }^{18}$ I think Gowers's remarks are much more plausible in the case of the FullBlooded Platonism vs. Fictionalist Nominalism dispute, rather than all possible Platonism vs. nominalism disputes, for some such disputes could lead to genuine differences in the rules that govern our usage of mathematical terminology (for instance, some nominalists might eliminate its usage altogether). 
by this brief treatment. My aim, however, has been to illustrate the kind of evidence that is compelling and the kind of arguments that really do threaten ontological disputes. The best strategy is to find specific reasons for thinking that the dispute in question is insular, rather than general principles that cast doubt on ontology as a whole.

\section{Conclusion}

In summary, I have argued that some familiar ontological disputes do matter, on the view that whether disputes are significant is determined by whether they are integrated with the rest of our theoretical projects. Specifically, I have argued that the dispute over whether concrete possible worlds exist is significant due to the fact that it arises naturally from broader concerns about the nature of modality, properties, and other intensional phenomena, and has consequences for various other questions in other areas of philosophy. Similarly, the dispute over whether there are material objects that coincide in space and time is significant, since it arises out of attempts to resolve certain paradoxes and has ramifications for the philosophy of language, epistemology, and other areas. I have also illustrated how the insignificance of some disputes might be demonstrated, using a version of the Platonism and nominalism dispute as an example. Together, these examples motivate the wider claim that many, though not all, ontological disputes are significant. To be sure, we need to carefully consider the details of those disputes, but when we do so and discover connections to other questions, issues and debates, we will have found some significant ontological disputes. ${ }^{19}$

$$
\begin{array}{r}
\text { Andrew Graham } \\
\text { University of Missouri - Kansas City } \\
222 \text { Cockefair Hall } \\
5100 \text { Rockhill Road } \\
\text { Kansas City, MO 64110-2499 } \\
\text { USA } \\
\text { grahamaj@umkc.edu }
\end{array}
$$

\footnotetext{
${ }^{19}$ Many thanks to Susanna Rinard, Stephen Yablo, Agustin Rayo, Robert Stalnaker, Matti Eklund, Stephen Maitzen, Mahrad Almotahari, and several anonymous reviewers for their helpful comments and suggestions.
} 


\section{References}

Adams, Robert. 1994. Leibniz: Determinist, Theist, Idealist. New York: Oxford University Press.

Balaguer, Mark. 1998. Platonism and Anti-Platonism in Mathematics. New York: Oxford University Press.

Bennett, Karen. 2009. Composition, Colocation and Metaontology. In Metametaphysics: New Essays on the Foundations of Ontology, ed. by David Chalmers, David Manley and Ryan Wasserman. New York: Oxford University Press.

Chalmers, David, David Manley and Ryan Wasserman. Metametaphysics: New Essays on the Foundations of Ontology. New York: Oxford University Press.

Field, Hartry. 1980. Science Without Numbers: A Defence of Nominalism. Malden: Blackwell.

Fine, Kit. 2003. The Non-Identity of a Thing and its Matter. Mind 112: 195-234.

Gibbard, Alan. 1975. Contingent Identity. Journal of Philosophical Logic 4: 187221.

Gowers, William Timothy. 2006. Does Mathematics Need a Philosophy? In 18 Unconventional Essays on the Nature of Mathematic, ed. by Reuben Hersh. New York: Springer Science and Business Media.

Graham, Andrew. Forthcoming. Structure and Significance in Metaphysics.

Kripke, Saul. 1971. Identity and Necessity. In Identity and Individuation, ed. by Milton Munitz. New York: New York University Press.

Leibniz, G. W. 1686. Primary Truths. In Philosophical Essays, translated and edited by Roger Ariew and Daniel Garber. Indianapolis: Hackett Publishing, 1989.

Lewis, David. 1983. New Work for a Theory of Universals. Australasian Journal of Philosophy 61: 343-377.

Lewis, David. 1986. On the Plurality of Worlds. Malden: Blackwell.

Mates, Benson. 1986. The Philosophy of Leibniz: Metaphysics and Language. New York: Oxford University Press.

Melia, Joseph. 2000. Weaseling Away the Indispensability Argument. Mind 109 (435): 455-480.

McMichael, Alan. 1983. A Problem for Actualism about Possible Worlds. Philosophical Review 92: 49-66.

Plantinga, Alvin. 1974. The Nature of Necessity. New York: Oxford University Press.

Plantinga, Alvin. 1976. Actualism and Possible Worlds. Theoria 42: 139-60.

Putnam, Hilary. 1979a. What is Mathematical Truth? In Mathematics Matter and Method: Philosophical Papers, Volume 1. New York: Cambridge University Press.

Putnam, Hilary. 1979b. Philosophy of Logic. In Mathematics Matter and Method: Philosophical Papers, Volume 1. New York: Cambridge University Press.

Quine, W. V. O. 1948. On What There Is. The Review of Metaphysics 2 (5): 21-38.

Quine, W. V. O. 1951. Two Dogmas of Empiricism. Philosophical Review 60 (1): $20-43$.

Quine, W. V. O. 1960. Word and Object. Cambridge: MIT Press.

Restall, Greg. 2003. Just What Is Full-Blooded Platonism? Philosophia Mathematica 11 (1): 92-91.

Sider, Theodore. 2001. Four-Dimensionalism. New York: Oxford University Press. Stalnaker, Robert. 1987. Inquiry. Cambridge: MIT Press.

Stalnaker, Robert. 2003. On What Possible Worlds Could Not Be. In Ways a World Might Be. New York: Oxford University Press.

Wiggins, David. 1968. On Being in the Same Place at the Same Time. The Philosophical Review 77 (1): 90-95. 
Yablo, Stephen. 1998. Does Ontology Rest on a Mistake? Aristotelian Society Supplementary Volume 72: 229-261.

Yablo, Stephen. 2002a. Go Figure: A Path Through Fictionalism. Midwest Studies in Philosophy 25: 72-102.

Yablo, Stephen. 2002b. Abstract Objects: A Case Study. Nous 36, supplementary volume 1: 220-240.

Yablo, Stephen. 2009. Must Existence-Questions Have Answers? In Metametaphysics: New Essays on the Foundations of Ontology, ed. by David Chalmers, David Manley and Ryan Wasserman. New York: Oxford University Press. 